\title{
Isolation and characterization of Vibrio parahaemolyticus from fish samples of Quetta, Pakistan
}

Roomeela ${ }^{1}$, AbdulSamad ${ }^{1}$, Muhammad Kamran Taj ${ }^{1}$, Saima $^{1}$, Muhammad Rizwan ${ }^{1 *}$, Mohammad Yousaf ${ }^{1}$, Yousaf Hassan ${ }^{1}$, Safiullah Khan Achakzai ${ }^{1}$, Muhammad Zahid ${ }^{2}$, Olena Pokryshko ${ }^{3}$, Silvia Diaconescu ${ }^{4}$ and Sundus Saifullah ${ }^{1}$

1. Center for Advanced studies in Vaccinology and Biotechnology University of Balochistan-Pakistan

2. Provincial TB control Program, Provincial Reference Laboratory, Fatima Jinnah General \& Chest Hospital, Quetta, Balochistan-Pakistan

3. Department of Microbiology, Virology and Immunology, Ternopil State Medical University-Ukraine

4. Accounting Services, Targu Jiu, Gorj-Romania

*Corresponding author's email: khanr6847@gmail.com

Citation

Roomeela, AbdulSamad, Muhammad Kamran Taj, Saima, Muhammad Rizwan, Mohammad Yousaf, Yousaf Hassan, Safiullah Khan Achakzai, Muhammad Zahid, Olena Pokryshko, Silvia Diaconescu and Sundus Saifullah. Isolation and characterization of Vibrio parahaemolyticus from fish samples of Quetta, Pakistan. Pure and Applied Biology. Vol. 7, Issue 2, pp595-602. http://dx.doi.org/10.19045/bspab.2018.70074

Received: 14/02/2018 Revised: 19/04/2018 Accepted: 28/04/2018 Online First: 05/05/2018

Abstract

Vibrio parahaemolyticus ( $V$. parahaemolyticus) is recognized as a major cause of sea food associated with gastroenteritis, mostly due to consumption of raw or undercooked fish. 30,000 food borne infections are caused by V.parahaemolyticus globally. This study was aimed to investigate the prevalence of V.parahaemolyticus in fish by using conventional Biochemical tests. A total of 100 fish samples, 50 fresh water fish (Cirrhinus margala, Catla catla, Labeo calbasu) + 50 salt water fish (Pompano, Barramunddi, Rohu) were collected randomly from different fish markets of Quetta. Out of 100 fish samples tested, $30(30 \%)$ were found positive for $V$. parahaemolyticus that is $44 \%$ from salt water fish and $16 \%$ from fresh water fish. Higher prevalence rate was observed during summer season and it was on peak in the months of AprilJuly. This study revealed that prevalence rate in fish is mostly due to improper refrigeration, insufficient cooking, cross contamination and improper handling during transportation.

Keywords: Biochemical test; Fish meat; Quetta; Vibrio parahaemolyticus

\section{Introduction}

Food borne illnesses can be defined as any disease of a poisonous and infectious nature caused by ingestion of water and uncooked sea food [1]. Globally food borne illnesses are major public health problem. Food borne diseases are a worldwide problem of great magnitude in terms of human sufferings and economic costs. It is one of the causes of morbidity and mortality in developed and developing countries in last two decades. In2005, it was estimated that 1.8 million deaths occurred due to diarrheal diseases, due 
to consumption of contaminated food and water [2]. Over the past few decades the incidences of Vibrio related illness have steadily increased. At least 30,000 food borne infections are caused by V.parahaemolyticus [3], typically from ingesting undercooked sea food. Food borne outbreaks caused by V.parahaemolyticus have been reported from many Asian countries, including India [4], China [5, 6], Korea [7, 8], Japan, Taiwan [9, 10] and Thailand. In Korea, Laos, and Indonesia, where raw seafood consumption is high, V.parahaemolyticus food infections are mainly caused by seafood.

$V$. parahaemolyticus, a member of Vibrionaceae family, is a gram negative, motile facultative anaerobe, straight or slightly curved bacilli, halophilic organism that in nature prefer eustrine and marine environment [11].It was initially reported as a source of food borne disease in an outbreak of food poisoning which occurred in Japan in 1950 [12].It has also been isolated from many countries in Asia, America, Australia, and Europe [13]. Best temperature for its growth is $30-37^{\circ} \mathrm{C}$ but is able to grow in a temperature range of $5-42^{\circ} \mathrm{C}$. Most favorable $\mathrm{pH}$ for its growth is 7.8 to 8.6 [14]. $\mathrm{V}$. parahaemolyticus is a ubiquitous human pathogen which may cause gastroenteritis when contaminated raw, insufficiently cooked or post heat-contaminated sea foods are consumed [15]. V. parahaemolyticus can cause clinical illness including gastroenteritis and septicemia which are characterized by dirraeoha, headache, vomiting, nausea, abdominal cramps and low-grade fever and third syndrome is wound infection [16].The main virulence factor associated with human gastroenteritis is called TDH (thermostable direct hemolysin). It is a very important virulence factor marker for the identification and differentiation of pathogenic $V$. parahaemolyticus [17].Tetracycline is the drug of choice for the treatment of severe Vibrio infections [18]. Additional treatments are combinations of broad-spectrum cephalosporins (e.g., ceftazidime), fluoroquinolone and doxycycline [19]. Consumption of raw, improper cooked or contaminated sea foods should be strongly avoided. Raw or cooked sea food products should be refrigerated or freezed and they must be consumed in a proper period of time [20].

\section{Materials and methods Sample collection}

Total of 100 Fish samples (50 fresh water fish Cirrhinus margala, Catla catla, Labeo calbasu) + 50 salt water fish Pompano, Barramunddi, Rohu) were randomly collected from fish market during the period of (Feb-Jul 2017) within Quetta city. Sample was collected in a sterile container and kept in a thermopol box filled with crushed ice and brought to Bacteriology laboratory of Center for Advanced Studies in Vaccinology and Biotechnology (CASVAB), University of Balochistan for further processing.

\section{Isolation and identification}

Isolation of $V$. parahaemolyticus was performed according to International Organization for Standardization (ISO) 21872-1:2007 [21] with some modifications. Briefly $25 \mathrm{~g}$ of meat from sample was placed in $225 \mathrm{ml}$ of alkaline peptone saline water (APSW) (Oxoid, England), crushed in the stomacher bags and was incubated at $41{ }^{\circ} \mathrm{C}$ for $6 \mathrm{hr}$. After incubation $1 \mathrm{ml}$ elicoite was taken and further sub cultured in to $10 \mathrm{ml}$ Alkaline Peptone Saline Water (APSW) broth and incubated at $41^{\circ} \mathrm{C}$ for $18 \mathrm{hr}$. After incubation a loop full of broth was streaked on to Thio-Sulfate Citrate Bile Salt Sucrose Agar (TCBSA) (Oxoid, England) and incubated at $37^{\circ} \mathrm{C}$ for $24 \mathrm{hr}$. suspected colonies of $V$. parahaemolyticus from selective medium were than streaked on to Saline Nutrient Agar (SNA) and incubated for $24 \mathrm{hr}$ at $37^{\circ} \mathrm{C}$. The colonies were subjected to slide preparation, Gram staining and microscopic analysis. Further confirmation 
was done by performing Biochemical tests such as oxidase, Triple sugar iron, Sucrose, Ornithine decarboxylase, Lysine decarboxylase, Arginine dehydroxylase, Citrate utilization, Sulphide indole motility, production of Indole and growth in peptone water with $0 \%, 2 \%, 6 \%, 8 \%, 10 \%$ Nacl.

\section{Results}

Out of 100 samples screened, $\mathrm{V}$. parahaemolyticus was detected in $30(30 \%)$ samples consisting of $22(44 \%)$ from salt water fish and $8(16 \%)$ from fresh water fish, as shown in (Figure 1).A higher concentration of $V$. parahaemolyticus was found in the fish collected during the month of (April- July), while minimum rate of prevalence observed during the month of March, as shown in (Figure 2). The isolates examined were Gram negative, short curved rod shape bacteria. $V$. parahaemolyticus was found Oxidase positive, halophilic and negative for Arginine dehydroxylase while positive for Ornithine and Lysine decarboxylase. All the strains fermented Dglucose without gas production, and Citrate was utilized when tested. All Isolates were grown at salt concentrations of $2 \%, 6 \%$, and $8 \%$ while on $0 \%$ and $10 \%$ salt concentration no growth was observed. The biochemical tests of $V$. parahaemolyticus isolates are shown in (Table 1).

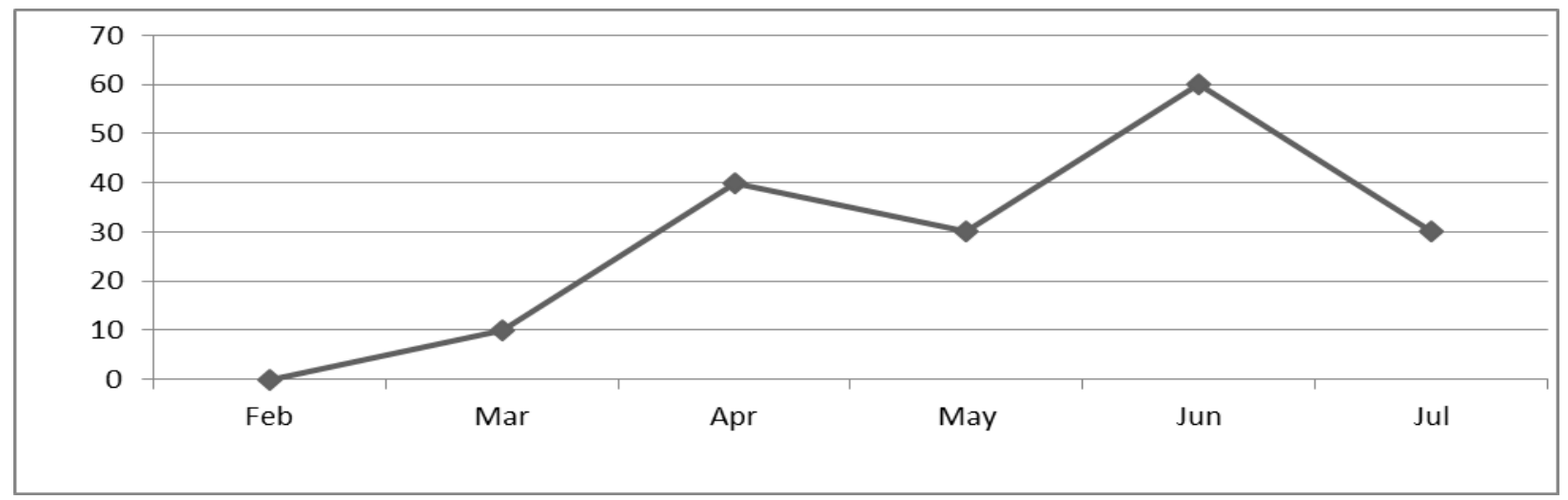

Figure 1. Prevalence of V.parahaemolyticus in salt water fish and fresh water fish

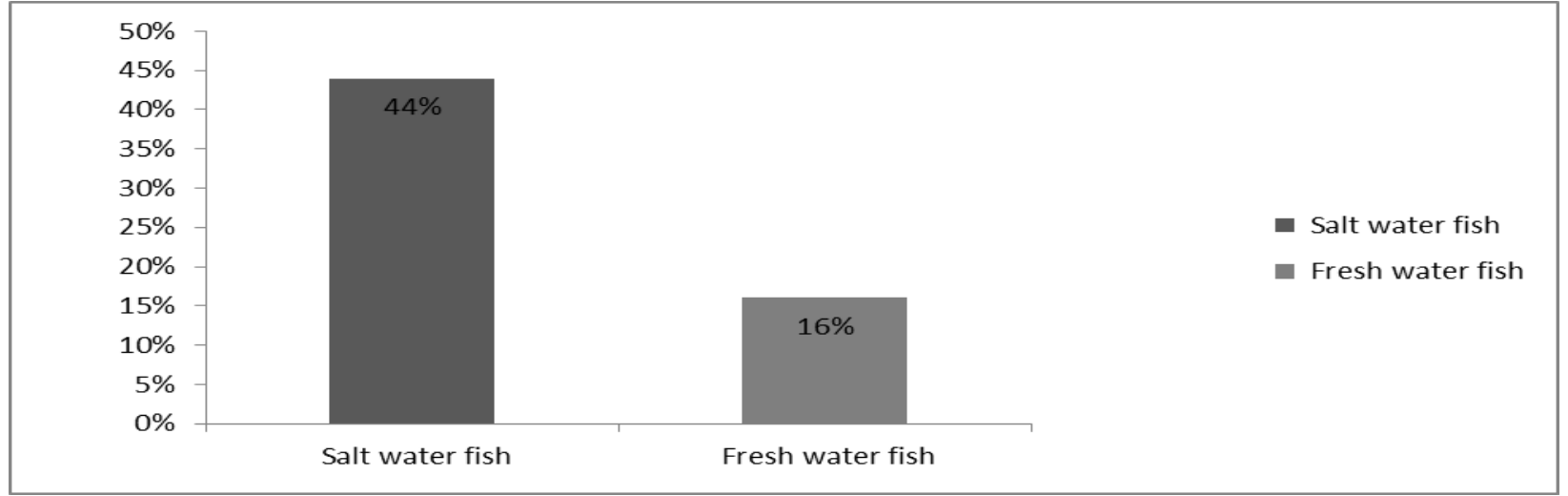

Figure 2. Prevalence of $V$. parahaemolyticus during summer season 
Table 1. Results of Biochemical tests for detection of $V$.parahaemolyticus

\begin{tabular}{|c|c|}
\hline $\begin{array}{c}\text { Test } \\
\text { (Media containing 1\% Nacl) }\end{array}$ & Vibrio parahaemolyticus \\
\hline Oxidase & + \\
\hline Production of gas (glucose) & - \\
\hline Lactose & - \\
\hline Sucrose & + \\
\hline Ornithine decarboxylase & - \\
\hline Lysine decarboxylase & - \\
\hline Arginine dehydroxylase & + \\
\hline Citrate Utilization & - \\
\hline Production of indole & + \\
\hline Growth in peptone water with & + \\
\hline $0 \%$ Nacl & + \\
\hline $2 \%$ Nacl & - \\
\hline 6\% Nacl & + \\
\hline $8 \%$ Nacl & \\
\hline $10 \%$ Nacl & \\
\hline
\end{tabular}

\section{Discussion}

$V$. parahaemolyticus is an important food borne bacterium and it is therefore important to acquire data on the presence of this organism in fresh water and salt water fish for future assessment. A total of 100 samples (50fresh water fish +50 salt water fish) revealed $22 \%$ of $V$. parahaemolyticus in salt water fish and $8 \%$ in fresh water fish by using conventional biochemical tests. This result is an agreement with [22].

The high prevalence of $V$. parahaemolyticus in common salt water fish during summer season (May-July) is in concordance with an earlier report of $50-70 \%$ prevalence of $V$. parahaemolytus in sea foods [23, 24]. However, in contrast to this, a prevalence of $45.83 \%$ in marine fish and $16.73 \%$ in fresh water fish has also been reported from Kolkata, India [25]. Occurrence of halophilic $V$. parahaemolyticus is also reported from India and West Germany in fresh water environment during summer season [26]. $V$. parahaemolyticus incidence in fresh water, as seen in present study is also reported from USA [27].
Being halophilic organism the occurrence of $V$. parahaemolyticus in the coastal area is not uncommon. But it is also isolated from fresh water fish [28]. The elevated level of $V$. parahaemolyticus in marine fish could be due to high salinity. Nearly comparable results are reported [29] in West Germany.

According to current study higher contamination rate in salt water fish is possible due to several biotic and abiotic parameters such as temperature, salinity, $\mathrm{pH}$ and turbidity. Mainly the sea food from the coastal region of South East Asia has hazard for the occurrence of $V$. parahaemolyticus from $20-70 \%$. The factor which contributes for the growth of $V$. parahaemolyticus is the salty and hot marine water [30].

In salt water fish the most important growth factor for $V$. parahaemolyticus is the temperature of water [31, 32]. According to current study the prevalence of $V$. parahaemolyticus in fish might be due to temperature, contaminated ice to cover the fish and mishandling. The results of current study showed high contamination of $V$. parahaemolyticus in fresh water and this is in 
accordance with a previous study by Depanjali in India [33, 34].

Anwar et al [35] isolated $45 \% \quad V$. parahaemolyticus from fish samples in Saudi Arabia and this was the most frequently reported vibrio specie by COVIS (The cholera and other vibrio illness Surveillance System). $25 \%$ prevalence of $V$. parahaemolyticus is reported in fresh water fish in USA [36]. The current study showed higher contamination rate than the other studies reported by Ottaviani et al [37], who observed $8 \%$ isolates of $V$. parahaemolyticus in Netherlands sea food. Tobin et al [38] and Velusamy et al [39] have found an incidence of $23 \% \mathrm{~V}$. parahaemolyticus in samples of fish and oyster and $33.3 \%$ in marine water samples in United States.

Yang [40] observed $22.8 \%$ prevalence in various sea foods in China. Jack and Ellen [41] reported higher incidence of $V$. parahaemolyticus in marine fish by using conventional methods in Italy.

In China [42] $92 \%$ to $95 \%$ higher prevalence of $V$. parahaemolyticus is reported, which is greater than the current study. Su and Liu [12] reported $92.5 \% \mathrm{~V}$. parahaemolyticus in Shanghai. In Florida $14.9 \%$ of iced and frozen seafood samples were contaminated with $V$. parahaemolyticus [43]. In this study high prevalence of $V$. parahaemolyticus showed that the lack of good hygiene, the absence of gloves for handling fish and the use of contaminated containers and ice during transportation contribute to prevalence of $V$. parahaemolyticus. It is imperative that routine screening and monitoring of fresh water fish samples for the presence of $V$. parahaemolyticus should be conducted at the retail level to reduce the occurrence of infection [44].

\section{Conclusion}

An elevated risk of contamination by pathogenic $V$. parahaemolyticus is associated with seafood consumption. To reduce the risk of getting infection by pathogenic
V.parahaemolyticus it is necessary to avoid raw or insufficiently cooked seafood consumption during warm summer periods. Establishment of an intensive and continuous monitoring system should be considered during transportation of fish.

\section{Authors' contributions}

Conceived and designed the experiments: A Samad, MK Taj \& Roomeela, Performed the experiments: Roomeela, Analyzed the data: Saima, M Rizwan, Safiullah, O Pokryshko \& $\mathrm{S}$ Diaconescu, Contributed materials/ analysis/ tools: M Yousaf, S Saifullah, Y Hassan \& M Zahid, Wrote the paper: Roomeela \& Saima.

\section{References}

1. Adams MR \& Moss MO (2003). Significance of food borne diseases. $J$ of Food Microbiol 163: 160-164.

2. Newell DG, Koopmans M \& Verhoef L (2010). Food borne diseases-the challenges of 20 Years ago still persist while new ones continue to emerge. Inter J of Food Microbial 139: 3-15.

3. Alagappan SM, Hanafiah A, Radu S, Neoh H \& Jamal R (2011). Rapid detection and E.test antimicrobial susceptibility testing of Vibrio parahaemolyticus isolated from sea food in Malaysia. J of Saudi Med 32: 400406.

4. Kubota K, Kasuga F, Iwasaki E, Inagaki S, Sakurai Y \& Komatsu M (2011). Estimating the burden of acute gastroenteritis and food borne illness caused by Vibrio parahaemolyticus by using population based telephone service data, Miyagi prefecture, Japan during (2005 - 2006). J food prot 74: 15921598.

5. Liu X, Chen Y, Wang X \& Ji R (2004). Food-borne diseases outbreaks in China. National food borne diseases surveillance system $J$ Hyg 33: 725-727.

6. Wang $\mathrm{Wu}$, Zhang QJ, hang S \& Wu K (2014). Prevalence, pathogenicity, and 
serotypes of Vibrio parahaemolyticus in shrimp from Chinese retail markets. Food control. J Food Cont 46: 81-85.

7. Alam MJ, Miyoshi S \& Shinoda S (2003). Studies on pathogenic Vibrio parahaemolyticus during warm weather in the Seto Inland Sea, Japan. J Environ Microbial 5: 706-710.

8. Yang Yu Y, Zhang P, Wu B \& Zhu B (2008). Putative type VI secretion system of Vibrio parahaemolyticus contribute to adhesion to cultures cell monolayer. Arch Microbial 194: 827835.

9. Lee JV, Shread P, Furniss A \& Bryant TN, (2008). Taxonomy and description of Vibrio fluvials. J Appl Bacteroi 50: 73-94.

10. Chen M, Wu Q, Zhang J, Yan Z \& Wang J (2014). Prevalence and characterization of Vibrio parahaemolyticus isolated from ready to eat foods in south china. Jo $f$ Biomed Environ 23: 32-36.

11. Yamamoto KT, Honda T, Miwatani S, Tamatsukuri \& S. Shibata (2008) Enzyme labeled oligonucleotide probes for the detection of the genes for thermostable direct hemolysin (TDH) $\mathrm{TDH}$, related hemolysin(TRH) of Vibrio parahaemolyticus. J of Microbial 38: 410-416.

12. Su YC \& Liu C (2007). Vibrio parahaemolyticus, a concern of seafood safety. Food Microbiol 24(6): 549-558.

13. Nishibuchi M (2006). Molecular identification Thompson. In FL, Austin B. Swings Washington DCJ the biology of Vibrios 44-64.

14. Martinez-Urtaza J, Simental L, Velasco D, DePaola A, Ishibashi M, Nakaguchi Y, Nishibuchi M, Carrera-Flores D, Rey-Alvarez C \& Pousa A (2005). Pandemic Vibrio parahaemolyticus O3:K6, Europe. Emerg Infect Dis 11(8): 1319-1320.
15. Urakawa H, Rivera ING, Thompson B \& Austin Swings FL (2006). Aquatic environment. $J$ the biology of vibrio 175 .

16. Özer S, Aslan G, Tezcan S, Bulduklu PS, Serin MS \& Emekdas G (2008). Genetic heterogeneity and antibiotic susceptibility of Vibrio parahaemolyticus strains isolated from Horse-Mackerel. Turk J Vet Anim Sci 32(2): 107-112.

17. Tyagi A, Saravanan V, Karunasagar I \& Karunasagar I (2009). Detection of Vibrio parahaemolyticus in tropical shellfish by SYBR green real-time PCR and evaluation of three enrichment media. Int J Food Microbiol 129: 124130.

18. Nemoto J, Sugawar C, Akahane $\mathrm{K}$, Hashimoto $\mathrm{K}$, Kojima T, Ikedo $\mathrm{M}$, Konuma H \& Hara-Kudo Y (2009). Rapid and specific detection of the thermostable direct hemolysin gene in Vibrio parahaemolyticus by loop mediated isothermal amplification. $J$ of Food Protect 72: 748-754.

19. Nair GB, Abraham M \& Natarajan R (2003). Distribution of Vibrio parahaemolyticus in fish harvested from Porto Novo (S. India) environs: a seasonal study. Canadian $J$ Microbiol26:1264-1269.

20. Lesne J, Fournier JM, sutra ML, Federighi JL \& Jouveet et al (2011). Dans Manuel de bacteriology alimentaire (Chapter vibrio) coordinators. Edition Polytechnia Paris 261-304.

21. ISO TS 21872 part 1 (2007). Microbiology of food and animal feeding stuffs- Horizontal method for the detection of potentially enteropathogenic Vibrio spp: Part 1. Detection of Vibrio parahaemolyticus and Vibrio cholera.

22. Hassan ZH, Zwartkruis-Nahuis JTM \& De Boer E (2012). Occurrence of Vibrio parahaemolyticus in retailed seafood in 
the Netherlands. Food Res Int 19(1):3943.

23. Shigeaki M, Atsumi NO, Toshio K, Takeshi \& Tetsuya I (2012). A CYytotoxic Acivity Type iii Secretion Effector of Vibrio parahaemolyticus targets vaculor $\mathrm{H}+$ ATPase subunit $\mathrm{c}$ and ruptures host cell lysossomes. Plos Pathogens 39: 42-33.

24. Scallan E, Hoekstra RM, Angulo FJ, Taxue RV\& Widdowson MA et al (2011). Food borne illness acquired in the United States; major pathogens. Emerg Infect 17: 7-15.

25. Sarkar BL, Nair GB, Banerjee AK \& Pal SC (2005). Seasonal distribution of Vibrio parahaemolyticus in fresh water environs and in association with fresh water fishes in Calcutta. Appl Environ Microbiol 49: 132-136.

26. Wong HC \& Lin CH (2001). Evaluation of typing vibrio parahaemolyticus by three pcr methods using specific primers. J Clin Microbial 39: 4233-4240.

27. Dechet A, Yu PA, Koram N \& Printer J (2006). Vibrio infections: An important cause of morbidity and mortality in the United States. Clin Infect Dis 46: 970-6.

28. Ramos RJ, Miotto LA, Miotto M, Silveira JN, Cirolini A, Silva HS, Rodrigues, Ddos P \& Vieira CR (2014). Occurrence of potentially pathogenic Vibrio in oysters (Crassos treagigas) and waters from bivalve mollusk cultivations in the South Bay of Santa Catarina. Rev Soc Bras Med Trop 47(3): 327-333.

29. Serracca L, Battistini R, Rossini I, Prearo M, Ottaviani D, Leoni F \& Ercolini C (2011). Vibrio virulence genes in fish collected from estuarine waters in Italy. Appl Microbiol. 53(4): 403-408.

30. Wang R, Zhong y, Gux, yuan j, Saeed AF \& Wang S (2015). The pathogenesis, detection, and prevention of vibrio parahaemolyticus. Front Microbial 43: 50-39.
31. Zhang H, Sun S, Shi w, Cui L \& Gu q (2013). Serotype, virulence and genetic traits of food borne and clinical vibrio parahaemolyticus isolates in shanghai china. Food-Borne Patho 10(9): 796804.

32. Deepanjali A, Kumar HS \& Karaunsagar I (2005). Seasonal variation in abundance of total and pathogenic Vibrio parahaemolyticus bacteria in oysters along the southwest cost of India. Appl Environ Microbial 71: 3575-3580.

33. Dileep V, Kumar HS, Kumar Y,Nishibuchi M \& Karauasagar I (2003). Application of Polymerase chain reaction for detection of Vibrio parahaemolyticus associated with typical sea food and coastal environment. Lett Appl Microbial 36: 423-427.

34. Pal D, Fletcher GC \& Das N (2010). Isolation and characterization of Vibrio parahaemolyticus from fish samples in Kolkata. Eur Rev Med Pharmacolsci 14: 545-549.

35. Chakraborty RD \& Surendren PK (2008). Occurrence and distribution of virulent strains of Vibrio parahaemolyticus in sea food marketed from Cochin (India). World $J$ MicrobBiotec 24: 1929-1935.

36. Ottaviani D, Leoni F, Rocchegiani E, Canonico C, Potenziani S, Santarelli S, Masini L, Sucota S \& Carraturo A (2010). Vibrio parahaemolyticus associated gastroenteritis in Italy. Persistent Occurrence of pandemic clone and emergence of serotype. Infect Dis 66: 452-455.

37. Ottaviani D, Leoni F, Rocchegiani E, Santarelli S, Canonico C, Masani L, Ditrani V \& Carraturo A (2008). First Clinical report of pandemic Vibrio parahaemolyticus infection in China. Microbial 46: 2144-2145. 
38. Tobin D, Angelo M, Smith AR, Bulens SN, Thomas S, Hodel M, Izumiya H, Akrakawa E, Morita M, Watanabe H, Marcin C \& Parsons MB (2008). Infections acquired in the United States. Clin Infect Dis 46: 970-6.

39. Velusamy V, Arashak K, Korostynska O, Oliwa K \& Adley C (2010). An overview of foodborne pathogen detection in the perspective of biosensors. J Biotec Adv 28: 232-254.

40. Yanng Z, Jiao X, Zhou X \& Cao G (2008). Isolation and characterization of Vibrio parahaemolyticus from fresh, low temperature preserved, dried and salted sea food products in two coastal areas of eastern China. Inter J food Microbiol 125: 279-285.
41. M Jack, S Ellen, P Dennis et al (2005). A multistate outbreak of Vibrio parahaemolyticus infection linked to raw sea food. J Food Protec 67: 21652170.

42. Buchhloz U, Brodhun S \& Brockman et al (2005). An outbreak in China associated with raw sea food. $J$ Food Protec 68(2): 273-276.

43. Elhadi N, Radu S, Chen CH \& Nishibuchi M (2004). Prevalence of potentially pathogenic Vibrio species in the seafood marketed in Florida. J Food Protec 67: 1469-1475.

44. Hara-Kudo Y, Nishina T, Nakagawa H, Konuma H, Hasegawa J \& Kumagai S (2001). Improved method for detection of Vibrio parahaemolyticus in seafood. Appl Environ Microb 67: 5819-5823. 